\title{
Adjuvant Chemotherapy in Breast Cancer: Back to the Future
}

'Innovators are inevitably controversial' Eva Le Gallienne

Adjuvant chemotherapy has been shown to be effective, on average, in reducing relapse and prolonging survival of women with breast cancer who underwent surgery. Attempts to extrapolate information useful for patient care have become complex since several hundreds of trials were conducted and results from studies might often be viewed as controversial. Expert consensus conferences provide a summary of useful indications to overcome the difficult extrapolation process [1], but yet controversies and lack of adherence to treatment guidelines are frequently observed [2].

The Austrian Breast and Colorectal Cancer Study Group (ABCSG) conducted their third randomized trial from 1984 for 7 years and accrued 263 patients with node-positive endocrine-'unresponsive' (according the biological definition at that time) breast cancer, of whom 18 were excluded from the analysis. They report their results at a median observation time of 100 months [3] almost being apologetic for not having shown a difference between the two treatment groups (AV$\mathrm{CMF} \times 1$ course vs. low-dose, unconventional $\mathrm{CMF}$ with an i.v. day 1 and $8 \mathrm{q} 4$ wks $\times 6$ courses).

Why are they shy about their report? Because they assume that the patients had a less effective treatment (justified by the 'efforts to avoid treatment-related toxicity...' as they claim in the discussion). In fact, both groups received low-dose cytotoxics. Furthermore, the trial was designed with at least three variables that were different from any cytotoxic adjuvant therapy considered to be a standard in the early 1980s: dose of chemotherapy in the control arm (CMF), duration of treatment of the experimental arm (AV-CMF), and use of anthracyclines, which was considered the first priority research question.
Is their shyness justified? We don't think so. There are two substantial merits in conception and conduct of this trial. The first is related to the fact that all patients had tumors which were classified as not expressing hormone receptors. This is an anticipation of the notion of tailoring adjuvant treatments according to specific biological features of breast cancer, especially within clinical trials. In the 1980s determination of ER and $\mathrm{PgR}$ was done with a labeling binding assay (LBA) [4]. One might ask whether a pathological review of ER and PgR expression, performed with immunohistochemistry on stored pathology material, would identify those pre- and perimenopausal patients whose treatment with cytotoxics for a longer duration might have influenced response due to ovarian function suppression. It is mainly these patients, with an endocrine-responsive disease who received a low-dose CMF combination, who are most likely get to benefit from endocrine effects of chemotherapy [5].

The second point of merit relates to the attempt to study the effects of a single course of chemotherapy in a subpopulation of patients in which such treatment has shown a surprising beneficial effect. The Ludwig Breast Cancer Study Group (currently, the International Breast Cancer Study Group), in fact, tested the issue of timing and duration and found, in a retrospective analysis, that the subpopulation which had the largest benefit from a single course of adjuvant (immediate postoperative administration) chemotherapy, was the one of postmenopausal women with node-negative breast cancer, who also had an endocrine-unresponsive disease [6]. Furthermore, a much more detailed analysis of timing of adjuvant chemotherapy across subpopulations led to the conclusion that endocrine responsiveness is the most important feature, beside age, which influences timing [7, 8], and probably also duration [9]. In the trial by the Austrian group, all patients had to start adjuvant therapy within 4 weeks of operation, an important feature which, however, does not allow to tackle

\begin{tabular}{ll}
\hline KARGER & @ 2003 S. Karger GmbH, Freiburg \\
Fax +497614520714 & Accessible online at: \\
$\begin{array}{l}\text { E-mail Information@Karger.de } \\
\text { www.karger.com }\end{array}$ & www.karger.com/onk
\end{tabular}

Marco Colleoni, MD

Division of Medical Oncology, Dept. of Medicine

European Institute of Oncology

Via Ripamonti 435, I-20141, Milan

Tel. +39 2 5-7489439, Fax -7489457

E-mail marco.colleoni@ieo.it 
the timing issue. Nevertheless, it might be hypothesized that if postmenopausal women with endocrine-unresponsive disease had some increased benefit from a single course of adjuvant treatment, while the premenopausal cohort with some endocrine responsiveness had an advantage from the longer duration of chemotherapy, the overall comparison between the two treatments will show no effect. It might therefore be wise to ask the authors whether the response to the treatments was different according to age (i.e., menopausal status). The sam- ple size is obviously too small to approach these analyses using a multivariate model (endocrine responsiveness by IHC, menopausal status and duration of treatment), but at least a simple binary analysis could satisfy the curiosity of those who think that a clinical trial should also aim at understanding rather than proving one's pet hypothesis and provide answers, which might enhance further research.

Marco Colleoni and Aron Goldhirsch, Milan

\section{References}

1 Goldhirsch A, Glick JH, Gelber RD: Meeting highlights: International Consensus Panel on the Treatment of Primary Breast Cancer. Seventh International Conference on Adjuvant Therapy of Primary Breast Cancer. J Clin Oncol 2001;19:3817-3827.

2 Du XL, Key CR, Osborne C, Mahnken JD, Goodwin JS: Discrepancy between consensus recommendations and actual community use of adjuvant chemotherapy in women with breast cancer. Ann Intern Med 2003;138:90-97.

3 Ploner F, Jakesz R, Hausmaninger H, Kolb R, Stierer M, Fridrik M, Steindorfer P, Gnant M, Haider K, Mlineritsch B, Tschurtschenthaler G, Steger G, Seifert M, Kubista E, Samonigg $\mathrm{H}$ and the Austrian Breast and Colorectal Cancer Study Group Randomized Trial: One cycle of antharacycline-contining adjuvant chemotherapy compared with six cycles of CMF treatment in node-positive hormone receptor-negative breast cancer patients Onkologie 2003; 26:115-119.

4 Elledge RM, Green S, Pugh R, Allred DC, Clark GM, Hill J, Ravdin P, Martino S, Osborne CK: Estrogen receptor (ER) and progesterone receptor (PgR), by ligand-binding assay compared with ER, $\mathrm{PgR}$ and $\mathrm{pS} 2$, by immuno-histochemistry in predicting response to tamoxifen in metastatic breast cancer: A Southwest Oncology Group Study. Int J Cancer 2000;89:111-117.
5 Pagani O, O’Neill A, Castiglione M, Gelber RD, Goldhirsch A, Rudenstam CM, Lindtner J, Collins J, Crivellari D, Coates A, Cavalli F, Thurlimann B, Simoncini E, Fey M, Price K, Senn HJ: Prognostic impact of amenorrhoea after adjuvant chemotherapy in premenopausal breast cancer patients with axillary node involvement: Results of the International Breast Cancer Study Group (IBCSG) Trial VI. Eur J Cancer 1998;34:632-640.

6 Ludwig Breast Cancer Study Group (Goldhirsch A, Study Coordinator): Prolonged disease-free survival after one course of perioperative adjuvant chemotherapy for node-negative breast cancer. N Engl J Med 1989;320:491-496.

7 Colleoni M, Bonetti M, Coates AS, CastiglioneGertsch M, Gelber RD, Price K, Rudenstam C.-M, Lindtner J, Collins J, Thürlimann B, Holmberg S, Veronesi A, Marini G, Goldhirsch A, for the International Breast Cancer Study Group: Early start of adjuvant chemotherapy may improve treatment outcome for premenopausal breast cancer patients with tumors not expressing estrogen receptors. J Clin Oncol 2000;18:584-590.
8 Colleoni M, Gelber S, Coates AS, CastiglioneGertsch M, Gelber RD, Price K, Rudenstam CM, Lindtner J, Collins J, Thürlimann B, Holmberg SB, Cortes-Funes H, Simoncini E, Murray E, Fey M, Goldhirsch A: Influence of endocrine-related factors on response to perioperative chemotherapy for patients with node-negative breast cancer. J Clin Oncol 2001;19:4141-4149.

9 Colleoni M, Litman HJ, Castiglione-Gertsch M, Sauerbrei W, Gelber RD, Bonetti M, Coates AS, Schumacher M, Bastert G, Rudenstam J-M Schmoor C, Lindtner J, Collins J, Thürlimann B, Holmberg SB, Crivellari D, Beyerle C, Neumann RLA, Goldhirsch A, for the International Breast Cancer Study Group and the German Breast Cancer Study Group: Duration of adjuvant chemotherapy for breast cancer: A joint analysis of two randomised trials investigating three versus six courses of CMF. Br J Cancer 2002;86:1705-1714. 